\title{
Orbito-Ethmoidal Rhabdomyosarcoma in an Adult Patient: A Case Report
}

\author{
Nguyen Tien Quang, Pham Tuan Anh, Hoang Thu Hang, Nguyen Phuong Anh \\ National Cancer Hospital of Viet Nam, Hanoi, Vietnam \\ Email: phamtuananh@hmu.edu.vn
}

How to cite this paper: Quang, N.T., Anh, P.T., Hang, H.T. and Anh, N.P. (2020) Orbito-Ethmoidal Rhabdomyosarcoma in an Adult Patient: A Case Report. Open Access Library Journal, 7: e6263.

https://doi.org/10.4236/oalib.1106263

Received: March 24, 2020

Accepted: April 17, 2020

Published: April 20, 2020

Copyright $\odot 2020$ by author(s) and Open Access Library Inc.

This work is licensed under the Creative Commons Attribution International License (CC BY 4.0).

http://creativecommons.org/licenses/by/4.0/

\begin{abstract}
Rhabdomyosarcomas (RMS) is one of the most common sarcomas in children but rare in adults. It can occur in any anatomic location but most often presents in the head and neck region. Herewith, we report a rare case of primary orbito-ethmoidal rhabdomyosarcoma in a 29 -year-old female. The patient underwent induction chemotherapy and achieved surprising results.
\end{abstract}

\section{Subject Areas}

Oncology

\section{Keywords}

Case Report, Rhabdomyosarcomas (RMS)

\section{Introduction}

Rhabdomyosarcomas (RMS), a malignant tumor of skeletal muscle origin, is one of the most common sarcomas in children. Although rhabdomyosarcoma (RMS) is rare in adults, accounting for 2 to 5 percent of adult sarcomas, approximately 40 percent of RMS cases arise in adults. It most often presents in the head and neck, approximately $35 \%$ - 40\% [1]. Experience in treatment of adults with RMS is limited. Some data suggest that compared with children, adults have an inferior outcome [2]. We report a case of 29-year-old woman who was diagnosed with orbito-ethmoidal rhabdomyosarcoma, and had complete response with chemotherapy.

\section{Case Presentation}

A 29-year-old woman presented with a gradual protrusion of the left eye of a six-month duration. It was associated with pain, redness and eye discharge. She had no history of trauma, fever or any systemic problems. There was a proptosis 
on the left-side eye. Palpation revealed a $5 \mathrm{~cm}$ firm mass in the superior of the orbit. The right eye examination was normal. The regional lymph nodes were not palpable (Figure 1).

The MRI of the head and neck showed a mass centered in the left nasoethmoidal region. It invaded the left side of frontal sinus, left orbit. It also extended to the meninges (Figure 2).

A biopsy was performed. Immunohistochemistry tests were positive for Desmin, myosin and negative for S-100, Melan-A, Synaptophysin and Chromogranin (Figure 3, Figure 4). Finally, the tumor was diagnosed as alveolar RMS.

She was treated with a combination of chemotherapy-VAC regimen, including Vincristine $1.5 \mathrm{mg} / \mathrm{m}^{2}$; Dactinomycine $0.045 \mathrm{mg} / \mathrm{kg}$ and Cyclophosphamide $1200 \mathrm{mg} / \mathrm{m}^{2}$. The patient responded well to this regimen after 4 cycles and cancer reached complete remission (Figure 5, Figure 6).

\section{Discussion}

Rhabdomyosarcoma (RMS) is the most common soft tissue tumor of childhood and is accounting for one-half of all soft tissue sarcomas after osteosarcoma. Approximately two-thirds of cases are diagnosed in children younger than six

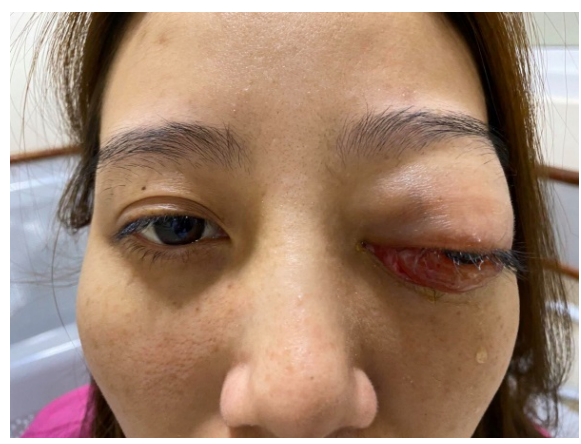

Figure 1. Left-side eye: proptosis, pain, redness and eye discharge.

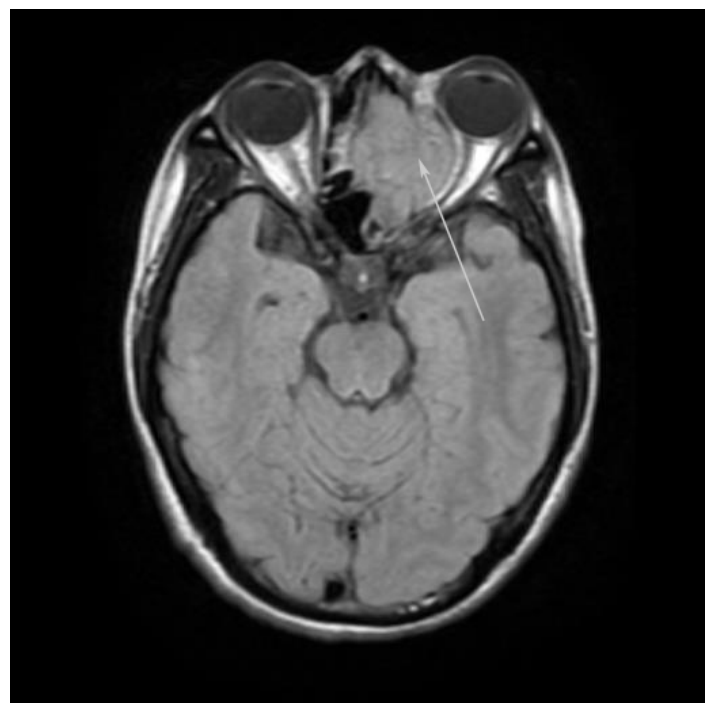

Figure 2. Mass centered in the left nasoethmoidal region (the white arrow). 


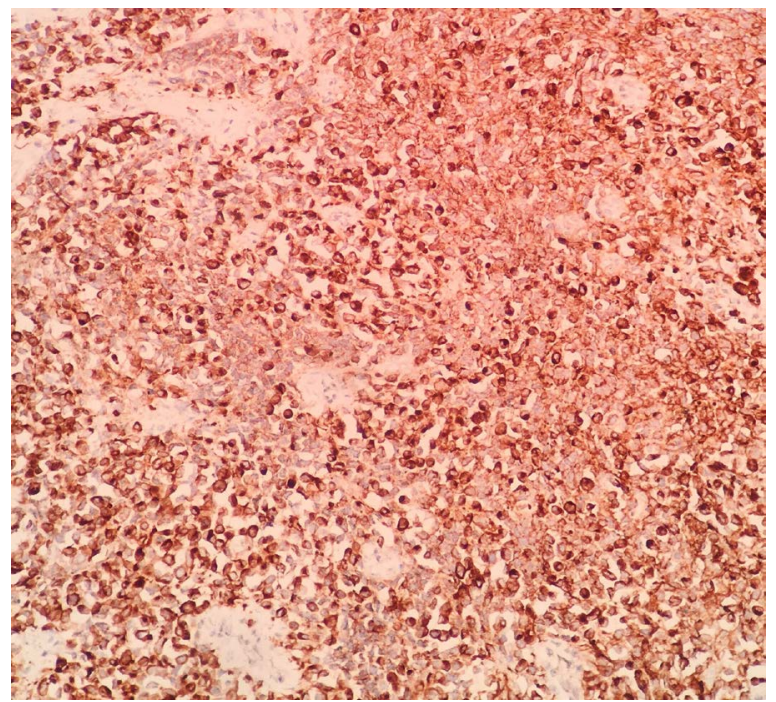

Figure 3. Desmin-positive staining.

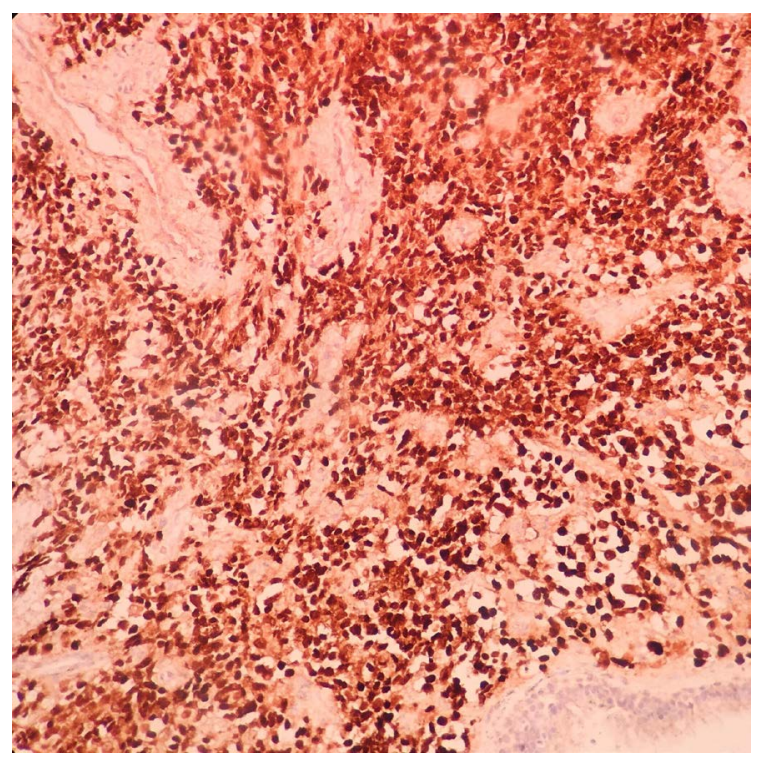

Figure 4. Myogenin-positive staining.

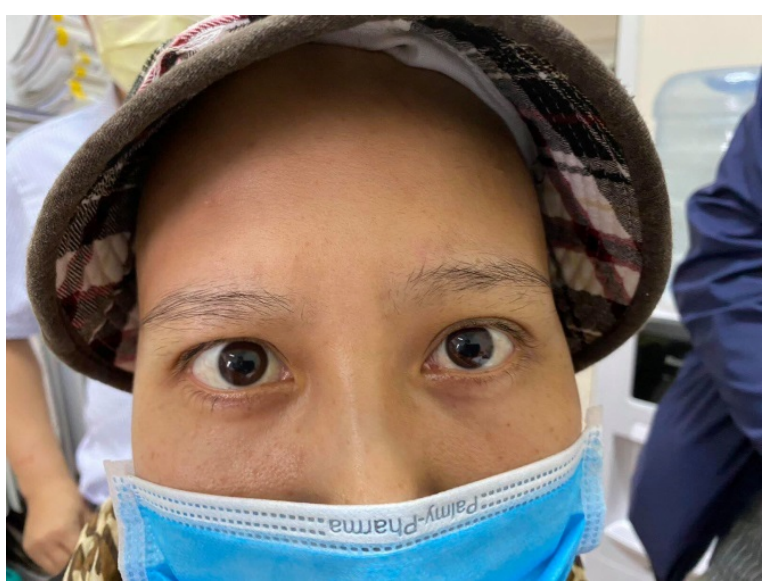

Figure 5. Her eye was treated with chemotherapy reached complete remission. 


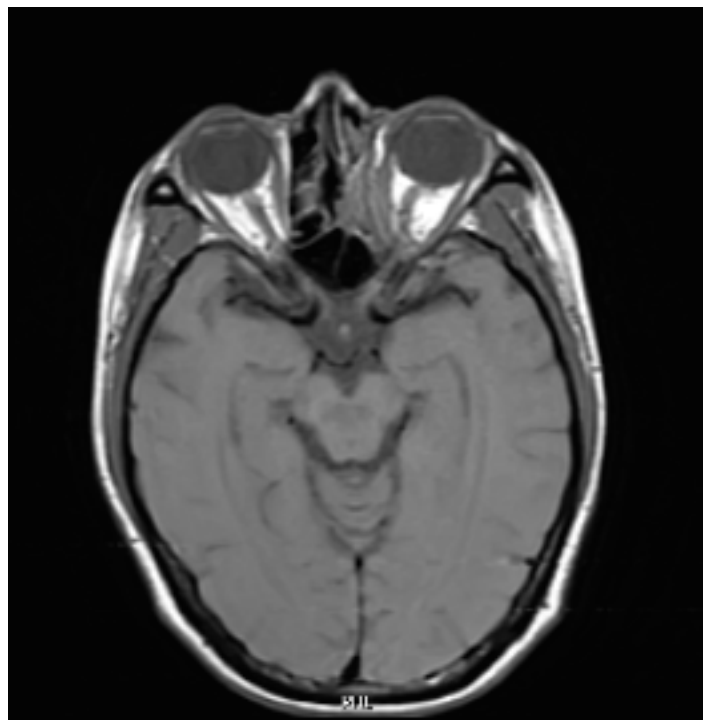

Figure 6. MRI image showed complete remission.

years of age, and there is a slight male predominance (male to female ratio between 1.3 and 1.5) [3]. Most cases of RMS are considered sporadic in origin, but there have been associations of RMS with several genetic syndromes (7 to 8 percent of the case). These syndromes associated with RMS include neurofibromatosis, Li-Fraumeni syndrome, Beckwith-Wiedemann syndrome, DICER1 syndrome, and Costello syndrome [4]-[10].

RMS has four different histopathological types: Embryonal, alveolar, pleomorphic and undifferentiated. The embryonal type is the most common, represents 70 percent of all RMS cases with an intermediate prognosis. Alveolar RMS is accounting for 21 percent of all cases with a relatively poorer prognosis. Alveolar RMS also presents with chromosomal translocations, including $\mathrm{t}(2 ; 13)$ ( $\mathrm{q} 35 ; \mathrm{q} 14)$ fused the PAX3 gene with FOXO1 gene and $t(1 ; 13)(p 36 ; q 14)$ fused the PAX7 gene with FOXO1 [11] [12].

Patients with RMS can present with an asymptomatic mass or with signs and symptoms that are associated with the primary tumor site and the presence or absence of distant metastases. RMS can affect any body part. The most common primary site is head and neck (approximately 35 to 40 percent), the second common site are the genitourinary tract and the extremities ( 25 percent and 20 percent). Head and neck RMS include parameningeal site (almost half of all head and neck case); the orbit (25 percent of all head and neck case) and other locations (25 percent including the scalp, parotid gland, oral cavity, pharynx, thyroid, and parathyroid glands, and neck) [13]. Parameningeal lesions can cause nasal, aural, or sinus obstruction with or without a mucopurulent or sanguineous discharge while orbital tumors cause proptosis and ophthalmoplegia. RMS arising from sites other than these typically present as a localized, painless enlarging mass.

RMS should undergo diagnostic biopsy and staging evaluation before starting therapy. There are two classifications for RMS into risk-based therapy groups: 
the clinical group (CG) and the tumor, node, metastasis (TNM) system. In 1972, the Intergroup Rhabdomyosarcoma Study Group (IRSG) developed the CG system. This system recognizes four disease categories based on the postoperative extent of disease with different prognoses (Table 1) [14].

TNM system has four disease stages $(1-4)$ based upon the site and size of the primary lesion, regional nodal involvement, and metastatic disease (Table 2) [15].

Table 1. Clinical grouping of rhabdomyosarcoma by the intergroup rhabdomyosarcoma study group (IRSG).

\begin{tabular}{|c|c|}
\hline Clinical group & Extent of disease/surgical result \\
\hline \multirow{2}{*}{ I } & A Localized tumor, confined to site of origin, completely resected \\
\hline & B Localized tumor, infiltrating beyond site of origin, completely resected \\
\hline \multirow{3}{*}{ II } & A Localized tumor, gross total resection, but with microscopic residual disease \\
\hline & B Locally extensive tumor (spread to regional lymph nodes), completely resected \\
\hline & $\begin{array}{l}\text { C Locally extensive tumor (spread to regional lymph nodes), gross total resection, } \\
\text { but microscopic residual disease }\end{array}$ \\
\hline \multirow[b]{2}{*}{ III } & A Localized or locally extensive tumor, gross residual disease after biopsy only \\
\hline & $\begin{array}{l}\text { B Localized or locally extensive tumor, gross residual disease after major resection } \\
\text { ( } \geq 50 \text { percent debulking) }\end{array}$ \\
\hline IV & $\begin{array}{l}\text { Any size primary tumor, with or without regional lymph node involvement, with } \\
\text { distant metastases, irrespective of surgical approach to primary tumor }\end{array}$ \\
\hline
\end{tabular}

Table 2. TNM staging system for rhabdomyosarcoma.

\begin{tabular}{|c|c|c|c|c|c|}
\hline Stage & Sites & $\begin{array}{l}\text { Tumor stage } \\
\text { invasiveness }\end{array}$ & T stage size & $\mathrm{N}$ & $\mathbf{M}$ \\
\hline 1 & $\begin{array}{l}\text { Orbit } \\
\text { Head and neck } \\
\text { Genitourinary } \\
\text { Biliary tract }\end{array}$ & $\mathrm{T}_{1}$ or $\mathrm{T}_{2}$ & $a$ or $b$ & Any N & $\mathrm{M}_{0}$ \\
\hline 2 & $\begin{array}{l}\text { Bladder/prostate } \\
\text { Extremity } \\
\text { Cranial parameningeal } \\
\text { Other }\end{array}$ & $\mathrm{T}_{1}$ or $\mathrm{T}_{2}$ & $\mathrm{a}$ & $\mathrm{N}_{0}$ or $\mathrm{N}_{\mathrm{X}}$ & $\mathrm{M}_{0}$ \\
\hline 3 & $\begin{array}{c}\text { Bladder/prostate } \\
\text { Extremity } \\
\text { Cranial parameningeal } \\
\text { Other }\end{array}$ & $\mathrm{T}_{1}$ or $\mathrm{T}_{2}$ & a & Any $\mathrm{N}$ & $\mathrm{M}_{0}$ \\
\hline 4 & All & $\mathrm{T}_{1}$ or $\mathrm{T}_{2}$ & $a$ or $b$ & $\mathrm{~N}_{0}$ or $\mathrm{N}_{1}$ & $\mathrm{M}_{1}$ \\
\hline & $\mathrm{T}$ : Tumor stage & \multicolumn{2}{|c|}{$\mathrm{N}$ : Regional nodes } & \multicolumn{2}{|c|}{ M: Metastases } \\
\hline $\begin{array}{r}\mathrm{T}_{1} \text { : Con } \\
\\
\mathrm{a}: \\
\mathrm{b}\end{array}$ & $\begin{array}{l}\text { nfined to anatomic site of } \\
\quad \text { origin } \\
\mathrm{T}_{2}: \text { Extension } \\
: \leq 5 \mathrm{~cm} \text { in diameter } \\
:>5 \mathrm{~cm} \text { in diameter }\end{array}$ & \multicolumn{2}{|c|}{$\begin{array}{c}\mathrm{N}_{0} \text { : Not clinically involved } \\
\mathrm{N}_{1} \text { : Clinically involved } \\
\mathrm{N}_{\mathrm{X}} \text { : Clinical status unknown }\end{array}$} & \multicolumn{2}{|c|}{$\begin{array}{c}\mathrm{M}_{0}: \text { No distant metastases } \\
\mathrm{M}_{1}: \text { Distant metastases } \\
\text { present }\end{array}$} \\
\hline
\end{tabular}


Currently, treatment for RMS is multimodality therapy, includes surgery, chemotherapy, and radiation therapy. The IRSG performed large collaborative randomized trials for the treatment of rhabdomyosarcoma. Since its inception, there have been five major trials, listed as the study I through V. As a result of these trials, the overall five-year survival rate of rhabdomyosarcoma at all sites has improved from 55 percent in IRS-I to 63 percent in IRS-II to approximately 71 percent in the IRS-III and IRS-IV protocols [16] [17] [18]. In head and neck tumors, the role of surgery is limited to initial diagnostic biopsy because of proximity to vital structures and cosmetic concerns. For COG treatment protocols, the three-drug combination of vincristine, actinomycin D, and cyclophosphamide (VAC) has been the gold-standard regimen of RMS. Different agents (Etoposide, Ifosfamide, Irinotecan, Topotecan, and Doxorubicin) or intensifying cyclophosphamide have attempted but they have not significantly improved clinical outcomes [19]. Radiation therapy (RT) is an important component of multimodality therapy for pediatric RMS. Induction chemotherapy, followed by concurrent chemoradiation, is the current standard of care for patients with the unresected disease and for patients with alveolar histology. RT is generally given after four cycles of chemotherapy.

In adults, there is a lack of standardized treatment. Generally, adults with RMS should be treated with the same treatment protocols as children although data are lacking with regards to some specifics, such as a way to integrate surgery, radiation, and chemotherapy in these patients or the total radiation dose.

Our patient at the time was diagnosed with RMS CG III. Therefore, she was treated with a VAC regimen. She had a clinical complete response to induction chemotherapy. She is intended to continue concurrent chemoradiation.

\section{Conclusion}

RMS is a rare head and neck tumor that occurs in the adult population and has a poor prognosis despite aggressive therapy. We believe that with multimodality therapeutic protocols and the best supportive care for complications may improve the prognosis of patients with this disease.

\section{Acknowledgements}

We have the patient's consent to report her clinical case.

\section{Conflicts of Interest}

The authors declare no conflicts of interest regarding the publication of this paper.

\section{References}

[1] Sultan, I., Qaddoumi, I., Yaser, S., et al. (2009) Comparing Adult and Pediatric Rhabdomyosarcoma in the Surveillance, Epidemiology and End Results Program, 
1973 to 2005: An Analysis of 2,600 Patients. Journal of Clinical Oncology, 27, 3391. https://doi.org/10.1200/JCO.2008.19.7483

[2] Little, D.J., Ballo, M.T., Zagars, G.K., et al. (2002) Adult Rhabdomyosarcoma: Outcome Following Multimodality Treatment. Cancer, 95, 377-388. https://doi.org/10.1002/cncr.10669

[3] Amer, K.M., Thomson, J.E., Congiusta, D., et al. (2019) Epidemiology, Incidence, and Survival of Rhabdomyosarcoma Subtypes: SEER and ICES Database Analysis. Journal of Orthopaedic Research, 37, 2226-2230. https://doi.org/10.1002/jor.24387

[4] Li, F.P. and Fraumeni Jr., J.F. (1969) Soft-Tissue Sarcomas, Breast Cancer, and Other Neoplasms. A Familial Syndrome? Annals of Internal Medicine, 71, 747-752. https://doi.org/10.7326/0003-4819-71-4-747

[5] Hartley, A.L., Birch, J.M., Marsden, H.B., et al. (1988) Neurofibromatosis in Children with Soft Tissue Sarcoma. Pediatric Hematology and Oncology, 5, 7-16. https://doi.org/10.3109/08880018809031246

[6] DeBaun, M.R. and Tucker, M.A. (1998) Risk of Cancer during the First Four Years of Life in Children from The Beckwith-Wiedemann Syndrome Registry. Journal of Pediatrics, 132, 398. https://doi.org/10.1016/S0022-3476(98)70008-3

[7] Matsui, I., Tanimura, M., Kobayashi, N., et al. (1993) Neurofibromatosis Type 1 and Childhood Cancer. Cancer, 72, 2746.

https://doi.org/10.1002/1097-0142(19931101)72:9<2746::AID-CNCR2820720936>3. $\underline{0 . \mathrm{CO} ; 2-\mathrm{W}}$

[8] Quezada, E. and Gripp, K.W. (2007) Costello Syndrome and Related Disorders. Current Opinion in Pediatrics, 19, 636-644. https://doi.org/10.1097/MOP.0b013e3282f161dc

[9] Gripp, K.W., Scott Jr., C.I., Nicholson, L., et al. (2002) Five Additional Costello Syndrome Patients with Rhabdomyosarcoma: Proposal for a Tumor Screening Protocol. American Journal of Medical Genetics, 108, 80-87. https://doi.org/10.1002/ajmg.10241

[10] Smith, A.C., Squire, J.A., Thorner, P., et al. (2001) Association of Alveolar Rhabdomyosarcoma with the Beckwith-Wiedemann Syndrome. Pediatric and Developmental Pathology, 4, 550-558. https://doi.org/10.1007/s10024001-0110-6

[11] Shapiro, D.N., Sublett, J.E., Li, B., et al. (1993) Fusion of PAX3 to a Member of the Forkhead Family of Transcription Factors in Human Alveolar Rhabdomyosarcoma. Cancer Research, 53, 5108-5112.

[12] Davis, R.J., D’Cruz, C.M., Lovell, M.A., et al. (1994) Fusion of PAX7 to FKHR by the Variant $\mathrm{t}(1 ; 13)(\mathrm{p} 36 ; \mathrm{q} 14)$ Translocation in Alveolar Rhabdomyosarcoma. Cancer Research, 54, 2869-2872.

[13] Months, S.R. and Raney, R.B. (1986) Rhabdomyosarcoma of the Head and Neck in Children: The Experience at the Children's Hospital of Philadelphia. Medical and Pediatric Oncology, 14, 288-292. https://doi.org/10.1002/mpo.2950140508

[14] Garnsey, L., Beltangady, M.S., Gehan, E., Ruymann, F., Webber, B., Hays, D.M., Crist, W.M., et al. (1990) Prognosis in Children with Rhabdomyosarcoma: A Report of the Intergroup Rhabdomyosarcoma Studies I and II. Intergroup Rhabdomyosarcoma Committee. Journal of Clinical Oncology, 8, 443-452. https://doi.org/10.1200/JCO.1990.8.3.443

[15] Crist, W.M., Anderson, J.R., Meza, J.L., et al. (2001) Intergroup Rhabdomyosarcoma Study-IV: Results for Patients with Nonmetastatic Disease. Journal of Clinical Oncology, 19, 3091-3102. https://doi.org/10.1200/JCO.2001.19.12.3091 
[16] Raney, R.B., Walterhouse, D.O., Meza, J.L., et al. (2011) Results of the Intergroup Rhabdomyosarcoma Study Group D9602 Protocol, Using Vincristine and Dactinomycin with or without Cyclophosphamide and Radiation Therapy, for Newly Diagnosed Patients with Low-Risk EMBR. Journal of Clinical Oncology, 29, 1312-1318. https://doi.org/10.1200/JCO.2010.30.4469

[17] Breneman, J., Meza, J., Donaldson, S.S., et al. (2012) Local Control with Reduced-Dose Radiotherapy for Low-Risk Rhabdomyosarcoma: A Report from the Children's Oncology Group D9602 Study. International Journal of Radiation Oncology, Biology, Physics, 83, 72. https://doi.org/10.1016/j.ijrobp.2011.06.2011

[18] Arndt, C.A., Hawkins, D.S., Meyer, W.H., Sencer, S.F., Neglia, J.P. and Anderson, J.R. (2008) Comparison of Results of a Pilot Study of Alternating Vincristine/Doxorubicin/ Cyclophosphamide and Etoposide/Ifosfamide with IRS-IV in Intermediate Risk Rhabdomyosarcoma: A Report from the Children's Oncology Group. Pediatric Blood \& Cancer, 50, 33-36. https://doi.org/10.1002/pbc.21093

[19] Arndt, C.A., Stoner, J.A., Hawkins, D.S., et al. (2009) Vincristine, Actinomycin, and Cyclophosphamide Compared with Vincristine, Actinomycin, and Cyclophosphamide Alternating with Vincristine, Topotecan, and Cyclophosphamide for Intermediate-Risk Rhabdomyosarcoma: Children's Oncology Group Study D9803. Journal of Clinical Oncology, 27, 5182-5188. https://doi.org/10.1200/JCO.2009.22.3768 